\title{
Research on Case Library Construction of Energy Loss in Country Distribution Networks with Grey Relational Analysis
}

\author{
Ze YUAN ${ }^{1, a}$, Xuefei $Z \mathrm{HU}^{1, \mathrm{~b}}$, Jianhua $\mathrm{YANG}^{1, c^{*}}$, Weizhou WANG ${ }^{2}$ \\ ${ }^{1}$ College of Information and Electrical Engineering, China Agricultural University, Beijing 100083, \\ China; ${ }^{2}$ Gansu Electric Power Research Institute, Lanzhou 730050, China \\ ayfz0328@163.com, b2364487797@qq.com, cyang.haag@163.com
}

\begin{abstract}
Keywords: energy loss, case library, distribution network, method of Grey Relational Analysis, regional differentiation, influence factors
\end{abstract}

\begin{abstract}
Some factors affect the energy loss in country distribution networks, including the load density, the load distribution, the grid structure and the operating condition of the distribution networks. As a result, the difference and the relation among these loss effect factors are considered, and the typical case library of energy loss in the distribution networks is built. On the basis of building some loss analysis scenes, the method of Grey Relational Analysis is used to evaluate the influence degree between energy loss rate and reference factors. The analysis software of the case library is developed and applied. Case studies show that there is some difference to these factors among different distribution networks and the difference can be suggested with the method, which provides a way to form the differential scheme of saving energy and reducing loss.
\end{abstract}

\section{Introduction}

With the development of construction and transformation in country distribution networks, power supply enterprises pay more attention to economical efficiency of the distribution networks operation. Meanwhile, there are different grid structures, load characteristics, operating conditions and equipment states among the country distribution networks. Therefore, it is necessary to analyze energy loss in the distribution networks with regional differential methods.

Nowadays, enough recognition is given with loss analysis and loss-reducing methods in distribution networks and a lot of valuable research production is found. The forefront of loss analysis and the research of loss reduction measures are introduced in [1], which mentions automatic network reconstruction, reactive power optimization and the location of the compensation capacitor determinateness. The development of the loss calculation models and methods for distribution networks, focusing on the influence factors to network loss management, is introduced in [2]. Based on network database, the software is developed for network loss calculation and loss reducing decision-making management in [3]. An evaluation index system of energy-saving conditions in distribution networks is put forward in [4]. So far, the application of typical cases for energy loss analysis and loss-reducing methods has not been mentioned.

In order to carry out the loss analysis of the country distribution networks and the comparison of the loss-reducing measures effectively, the case library of the regional loss of the networks should be established. The energy loss of the regional distinction in different prefectures is studied in this paper. The method of Grey Relational Analysis (GRA) is applied to assess influence degree between energy loss rate and reference orders. The analysis software of the case library is developed and some functions are realized for the distribution networks. The given example suggests that the method and the software are effective to the promotion of the loss analysis and energy saving in the distribution networks.

\section{Influence Factors Analysis}

According to the difference of the country distribution networks, the specific conditions of the regional distinction should be considered to study the influence factors that affect the energy loss in 
the distribution networks obviously and their influence degree. In order to analyze these factors, it is necessary to have a profound understanding of the structure types and operation modes of the distribution networks and then use appropriate theoretical methods to analyze the major factors.

In the process of building loss case library, the following four ways are used to analyze the influence factors, such as the partitioned region analysis, the partitioned voltage analysis, the partitioned medium voltage (MV) line analysis and partitioned transformer district analysis. These ways provide different perspectives to study and analyze energy loss by dividing the overall distribution networks into different parts and different voltage levels [5]. The major influence factors are shown in Table 1.

Table 1 Major influence factors of energy loss in distribution networks

\begin{tabular}{ll}
\hline \multicolumn{1}{c}{ Part } & \multicolumn{1}{c}{ Major influence factors } \\
\hline Overall networks & Cable rate; Ring network rate; Average load rate of distribution transformers; Average \\
load rate of distribution lines; Load density; Average power factor \\
$\begin{array}{l}\text { distribution networks } \\
\text { MV distribution }\end{array}$ & $\begin{array}{l}\text { Distribution line length; Cross-sectional area of wires; Main transformer capacity; Main } \\
\text { transformer type }\end{array}$ \\
$\begin{array}{l}\text { networks } \\
\text { Low voltage }\end{array}$ & Power factor ( $(\varphi)$; Distribution transformer capacity (t); Branch load rate (r) \\
distribution networks & Line conditions; Load curves; Three-phase unbalance degree; Electric energy meters \\
\hline
\end{tabular}

\section{Method of GRA}

To assess the influence degree between energy loss rate and reference orders, some data analysis methods could be used, including GRA, sensitivity analysis, and so on [4, 6]. The GRA method is a basic method of the grey system theory for systems analysis and is based on both qualitative analysis and quantitative analysis. The application of GRA is introduced as follows.

First, the network loss analysis indicators are used to characterize the influence degree. The energy loss rate and its influence factors constitute the main index system of the distribution network loss analysis. For the $n$ analysis scenes which are generated by multiple distribution network ones, taking MV distribution networks as an example, the energy loss rate is chosen as the main factor sequence $A$, and quantitative influence factors mentioned in Table 1 are set as the reference factors sequences $B_{\mathrm{i}}$, $i=\mathrm{l}, \mathrm{w}, \mathrm{v}, \varphi$, $\mathrm{t}$ and $\mathrm{r}$, as shown in Eq. 1 and Eq. 2.

$$
\begin{aligned}
& A=[a(1), a(2), a(3), \ldots, a(n)] \\
& B_{i}=\left[b_{i}(1), b_{i}(2), b_{i}(3), \ldots, b_{i}(n)\right], i=l, w, v, \varphi, t \text { and } r
\end{aligned}
$$

The main factors sequence $A$ is standardized according to Eq. 3 and Eq. 4 . The standard procedure of the reference factors sequences $B_{\mathrm{i}}$ is similar.

$$
\begin{aligned}
& A^{\prime}=\left[a^{\prime}(1), a^{\prime}(2), a^{\prime}(3), \ldots, a^{\prime}(n)\right] \\
& a^{\prime}(k)=\frac{a(k)-\min a(k)}{\max a(k)-\min a(k)}, k=1,2,3, \ldots, n
\end{aligned}
$$

Where $\min a(k)$ is minimum value and $\max a(k)$ is maximum value of the main factors sequence A. The difference, symbolized by $\Delta_{i}(k)$, between the standardized reference factor sequences $B_{\mathrm{i}}$ ' and the standardized main factor sequence $A^{\prime}$ can be calculated, as shown in Eq. 5.

$$
\Delta_{i}(k)=\left|b_{i}^{\prime}(k)-a^{\prime}(k)\right|, i=l, \mathrm{w}, v, \varphi, t \text { and } r
$$

Then the extreme value of $\Delta_{i}(k)$ could be found, symbolized by $\Delta \max$ and $\Delta \min$ respectively. The relational factors $\gamma_{i}(k)$ are defined as Eq.6.

$$
\gamma_{i}(k)=\frac{\Delta \min +\rho \Delta \max }{\Delta_{i}(k)+\rho \Delta \max }, i=l, w, v, \varphi, t \text { and } r
$$

Where $\rho$ is distinguishing coefficient and could be chosen as 0.5 generally. And the grey relational factors $\gamma_{i}$ are solved in Eq.7. 


$$
\gamma_{i}=\frac{1}{n} \cdot \sum_{k=1}^{n} \gamma_{i}(k), i=l, \mathrm{w}, v, \varphi, t \text { and } r
$$

\section{Functional Design of Analysis Software}

The analysis software of the case library is developed in C\# with Microsoft Visual Studio 2010. And the software functional design, structure design and database design are done.

The software mainly consists of five functional modules.

1) Users management module. This module includes users login, logout, register and delete, which makes sure the security and stability of the software.

2) Case library management module. This module is mainly for users to complete case information management, i.e. adding, modifying, deleting and exporting information.

3) Cases query module. The four ways to query for energy loss cases can be provided in the module, such as partitioned region query, partitioned voltage query, partitioned MV lines query and partitioned transformer district query. These ways correspond to the four analysis ways mentioned before.

4) Cases comparison module. Based on the cases query module, it chooses two similar and comparable cases to compare.

5) Help module. It offers some essential function description, guided aids and copyright notice.

\section{Illustrative example}

To verify the feasibility of GRA in the energy loss factors analysis, three MV lines in a country is chosen for energy loss analysis by using the software. The MV main lines are sectioned according to the location of distribution transformers and the branch of the lines. The influence of cross-sectional area of wires is indicated by average resistance of the sectionalized distribution line. The loss analysis scenes are built and the known information is shown in Table 2.

Table 2 Information of energy loss rate and reference factors in a country distribution network

\begin{tabular}{ccccccccc}
\hline Name & Sence & $\begin{array}{c}\text { Energy } \\
\text { loss } \\
\text { rate } / \%\end{array}$ & $\begin{array}{c}\text { Sectionalized } \\
\text { distribution } \\
\text { line length } \\
/ \mathrm{m}\end{array}$ & $\begin{array}{c}\text { Cross-sectional } \\
\text { area of wires } \\
\text { (shown as } \\
\text { resistance) } / \Omega\end{array}$ & $\begin{array}{c}\text { Operating } \\
\text { voltage } \\
/ \mathrm{kV}\end{array}$ & $\begin{array}{c}\text { Power } \\
\text { factor }\end{array}$ & $\begin{array}{c}\text { Distribution } \\
\text { transformer } \\
\text { capacity/kV } \\
\mathrm{A}\end{array}$ & $\begin{array}{c}\text { Branch } \\
\text { load } \\
\text { rate } / \%\end{array}$ \\
\hline MV & 1 & 2.51 & 346.5 & 0.352 & 10.0 & 0.98 & 2680 & 6.7 \\
line & 2 & 2.48 & 353.8 & 0.348 & 9.9 & 0.90 & 2775 & 7.1 \\
1\# & 3 & 2.45 & 360.8 & 0.342 & 9.95 & 0.99 & 2850 & 7.2 \\
\hline MV & 1 & 5.23 & 395.1 & 0.337 & 10.0 & 0.98 & 8025 & 38.5 \\
line & 2 & 5.21 & 401.5 & 0.330 & 9.9 & 0.90 & 8275 & 37.1 \\
2\# & 3 & 5.14 & 412.6 & 0.320 & 9.95 & 0.99 & 8350 & 37.2 \\
\hline MV & 1 & 4.52 & 132.3 & 0.375 & 10.0 & 0.98 & 3565 & 29.6 \\
line & 2 & 4.48 & 135.7 & 0.356 & 9.9 & 0.90 & 3915 & 28.4 \\
3\# & 3 & 4.45 & 139.2 & 0.332 & 9.95 & 0.99 & 4030 & 30.1 \\
\hline
\end{tabular}

The operation of the case analysis software is shown in Fig.1. And the result is shown in Table 3.

As the calculation results shown in Table 3, the influence degree of these factors among the MV lines is quite different. For MV line 1\#, the factors of greater influence on energy loss include the cross-sectional area of wires and the branch load rate. A series of loss reduction measures, such as modifying wire type of MV line and adjusting distribution of load, should be adopted. For MV line 2\#, the cross-sectional area of wires still influences the energy loss rate apparently, but the distribution line length becomes more influential. The most influential factors change for the loss of MV line 3\#. The branch load rate and distribution transformer capacity should also be taken into consideration when the loss-reducing scheme is designed. The differences and the similarities among three MV lines in a country distribution network are reflected to the results of GRA calculation, which suggest that the differences and the similarities are able to be quantified and analyzed with appropriate data analysis methods. 

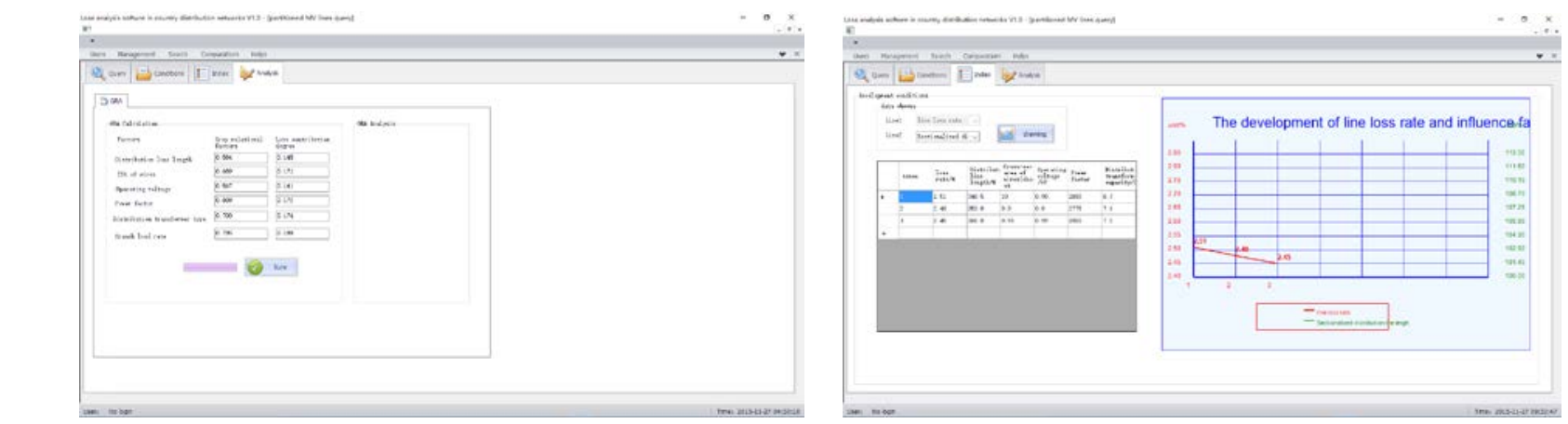

Fig.1 The process of GRA calculation

Table 3 The results of GRA calculation

\begin{tabular}{clcccccc}
\hline Influence & factors & $\begin{array}{c}\text { Sectionalized } \\
\text { distribution } \\
\text { line length } \\
/ \mathrm{m}\end{array}$ & $\begin{array}{c}\text { Cross-sectional } \\
\text { area of wires } \\
\text { (shown as } \\
\text { resistance) } / \Omega\end{array}$ & $\begin{array}{c}\text { Operating } \\
\text { voltage } \\
/ \mathrm{kV}\end{array}$ & $\begin{array}{c}\text { Power } \\
\text { factor }\end{array}$ & $\begin{array}{c}\text { Distribution } \\
\text { transformer } \\
\text { capacity } \\
/ \mathrm{kVA}\end{array}$ & $\begin{array}{c}\text { Branch load } \\
\text { rate/\% }\end{array}$ \\
\hline \multirow{3}{*}{ GRA factors } & MV line 1\# & 0.560 & 0.778 & 0.556 & 0.673 & 0.582 & 0.689 \\
& MV line 2\# & 0.739 & 0.901 & 0.590 & 0.629 & 0.559 & 0.726 \\
& MV line 3\# & 0.584 & 0.778 & 0.567 & 0.689 & 0.700 & 0.795 \\
\hline
\end{tabular}

\section{Conclusions}

There is quite difference in the influence degree between the energy loss rate and the reference factors according to the practical experience and the theoretical analysis. GRA can be applied to solve the evaluation problem of loss influence factors in a country distribution network. The basic framework of case library analysis software is built and some fundamental functions are realized. Cases studies indicate that the differences and similarities of influence degree in different kinds of distribution networks could be distinguished. According to the analysis results, it is feasible to find some suitable measures to reduce energy loss.

\section{Acknowledgements}

This work is financially supported by the Science and Technology Project of SGCC (SGGSKY00JNJS1500075).

\section{References}

[1] Juelsgaard M, Andersen P and Wisniewski R: IEEE Trans. on SG Vol. 5 (2014), p. 2133.

[2] J.R.C. Orillaza, Del Mundo R and J.A.C Miras: Development of Models and Methodology for the Segregation of Distribution System Losses for Regulation. TENCON (2006), p.1.

[3] Huaiyu CUI: The General Design of Line Loss Online Computation Analysis and Reduction Loss Assistanct Policy System for Distribution Networks. NCEPU (2008).

[4] Zejing QIU, Tieyuan XIANG, Hongkun CHEN and Jie YIN: China Rural Water and Hydropower Vol. 4(2013), p. 106.

[5] Yingshui NIU: Power Network Loss Reduction and Energy Saving Technological Applications and Cases Analysis (China Electric Power Press, China 2014).

[6] Binyu WANG: Research on Loss Analysis and Reducing Technology Choosing Method in Citi's MV/LV Distribution Network. CQU (2014). 